\title{
Mechanisms of miR-128-3p in inhibiting osteoblast differentiation from bone marrow-derived mesenchymal stromal cells
}

\author{
WEN ZHANG $^{1 *}$, YU ZHU ${ }^{1 *}$, JUNSHENG CHEN $^{2}$, JIAXING WANG $^{1}$, CHEN YAO $^{1}$ and CHEN CHEN ${ }^{1}$ \\ ${ }^{1}$ Department of Orthopedic Surgery, Shanghai Jiao Tong University Affiliated Sixth People's Hospital, \\ Shanghai Jiao Tong University, Shanghai 200233; ${ }^{2}$ Engineering Research Center of Cell and Therapeutic Antibody, \\ Ministry of Education, School of Pharmacy, Shanghai Jiao Tong University, Shanghai 200240, P.R. China
}

Received November 21, 2019; Accepted May 27, 2020

DOI: $10.3892 / \mathrm{mmr} .2020 .11600$

\begin{abstract}
The authors' previous study demonstrated that miR-128 may exert an inhibitory effect on the osteogenic differentiation of bone marrow-derived mesenchymal stem cells (BM-MSCs), but its downstream mechanisms remain to be elucidated. The aim of the present study was to investigate the microRNA (miRNA/miR) and mRNA profiles of differentiated and undifferentiated BM-MSCs and explore new downstream targets for miR-128. The sequencing datasets of GSE107279 (miRNA) and GSE112318 (mRNA) were downloaded from the Gene Expression Omnibus database. The differentially expressed miRNAs (DEMs) and genes (DEGs) were identified using the DESeq2 method. The target genes of DEMs were predicted by the miRwalk 2.0 database. The hub target genes of miR-128 were screened by constructing the protein-protein interaction (PPI) network and module analysis. The expression levels of miR-128 and crucial target genes were validated by reverse transcription-quantitative (RT-q) PCR before or after transfection of miR-128 mimics to BM-MSCs. The miRNA expression profile analysis identified miR-128 as one of the significantly downregulated DEMs (total 338) in differentiated BM-MSCs compared with the undifferentiated control. A total of 103 predicted target genes of miR-128-3p were overlapped with upregulated DEGs. By calculating the topological properties of each protein in the PPI network, 6 upregulated genes (KIT, NTRK2, YWHAB, $G A B 1, A X I N 1$ and RUNX1; fold change was the highest for $N T R K 2$ ) were considered to be hub genes. Of these, 4 were enriched in module 4 (RUNXI, KIT, GABI and AXINI;
\end{abstract}

Correspondence to: Dr Chen Chen, Department of Orthopedic Surgery, Shanghai Jiao Tong University Affiliated Sixth People's Hospital, Shanghai Jiao Tong University, 600 Yi Shan Road, Xuhui, Shanghai 200233, P.R. China

E-mail: chenchen2019@aliyun.com

${ }^{*}$ Contributed equally

Key words: bone marrow-derived mesenchymal stem cells, osteogenic differentiation, miR-128-3p, RUNX1, YWHAB, NTRK2
$R U N X 1$ was particularly crucial as it can interact with the others), while one was enriched in module 7 (YWHAB). The expression levels of miR-128 and these 6 target genes during the osteogenic differentiation were experimentally confirmed by RT-qPCR. In addition, the expression levels of these 6 genes were significantly reversed after transfection of miR-128-3p mimics into rat BM-MSCs compared with the miR-control group. These findings indicated that miR-128-3p may inhibit the osteoblast differentiation of BM-MSCs by downregulation of these 6 genes, particularly RUNX1, YWHAB and NTRK2.

\section{Introduction}

There has been a consensus that bone marrow-derived mesenchymal stem cells (BM-MSCs) are an ideal cell source for cell-based therapy of various bone-related diseases $(1,2)$ because they can differentiate into osteoblasts, which are the most important cells responsible for bone development and remodeling (3). However, their clinical application remains not widely accepted and treatment outcomes still require additional confirmation with larger sample sizes and control experiments (4). These highlight the need to further understand the molecular mechanisms of osteogenic differentiation in order to improve the differentiation and therapeutic efficiency of BM-MSCs.

microRNAs (miRNAs) are a class of small, non-coding RNAs of approximately $22 \mathrm{nt}$ in length that exert roles by negatively regulating the expression of target mRNAs via specific binding to their 3 '-untranslated region (3'-UTR). Recently, several miRNAs have been found to be associated with the differentiation of BM-MSCs. For example, Zhang et al (5) revealed that miR-664a-5p was upregulated in osteoblast-differentiated human BM-MSCs compared with control and this upregulation was positively correlated with the expression of osteogenic genes (RUNX2, ALP and $O C N$ ). Overexpression of miR-664a-5p stimulated the osteogenic differentiation of BM-MSCs, whereas an opposite effect was observed when it was knocked down. Luciferase reporting assay revealed that $H M G A 2 \mathrm{mRNA}$ was a direct target of miR-664a-5p. Overexpression of $H M G A 2$ rescued the effects of miR-664a-5p on osteogenic differentiation (5). Ge et al (6) reported that overexpression of miR-374b significantly induced the osteogenic differentiation of mouse BM-MSCs, 
showing increased $A L P$ activity and the expression of $R U N X 2$, $O P N$ and $O C N$. Further analysis of the mechanism revealed that miR-374b may bind to PTEN to mediate its functions (6). Huang et al (7) demonstrated that overexpression of miR-320a downregulated HOXA1O and then significantly inhibited osteogenesis of BM-MSCs, as determined by the downregulation of the osteogenic markers RUNX2,ALP and $O C N$ and the inhibition of $A L P$ activity and matrix mineralization; while ectopic expression of HOXA10 attenuated miR-320a-induced inhibitory effects on osteogenic differentiation of BM-MSCs. miR-125a-3p and miR-125b have been revealed to specifically regulate the expression of GIT ArfGAP 1 (GITI) and BMPRIb to inhibit the osteoblastic proliferation and differentiation from BM-MSCs, respectively $(8,9)$. miR-223 was identified to be gradually downregulated during osteogenic differentiation of BM-MSCs, accompanied by the upregulated expression of its target gene DHRS3 (10). These findings revealed the importance of investigating the miRNAs and their target genes to explain the osteogenic differentiation mechanisms of BM-MSCs.

In our previous study, it was demonstrated that miR-128 was downregulated by $58.8 \%$ in osteogenic treatment for human BM-MSCs and that miR-128 may inhibit the osteogenic differentiation through suppression of the vascular endothelial growth factor pathway (11). However, studies on miR-128 remain rare and its downstream mechanisms for osteogenic differentiation are still not well understood. The present study aimed to further elucidate the molecular mechanisms of miR-128 during the osteogenic differentiation of BM-MSCs by bioinformatic analyses of miRNA (12) and mRNA sequencing datasets which were collected from a public database. The predicted target genes were also validated by in vitro experiments in which miR-128 mimics were introduced. The present study may provide new insights for elucidating the mechanisms of miR-128 and identifying potential therapeutic targets to promote bone anabolism.

\section{Materials and methods}

High-throughput datasets. The high-throughput datasets of miRNAs and mRNAs in BM-MSCs before or after osteoblast differentiation were available from the Gene Expression Omnibus (GEO) database (http://www.ncbi.nlm.nih.gov/geo/) under accession number GSE107279 (platform: GPL11154, Illumina HiSeq 2000) (12) and GSE112318 (platform: GPL20795, HiSeq X Ten) (13), respectively. GSE107279 (12) included 3 undifferentiated human BM-MSC samples and 21 differentiated samples which were collected after induction for $12,24 \mathrm{~h}, 3,10$ and 13 days in osteogenic medium. GSE112318 (13) contained one undifferentiated human BM-MSC sample and one differentiated sample which was induced for 2 weeks in osteogenic medium. To identify the link between miRNAs and mRNAs, the present study only used the 13-day data of GSE107279 dataset (12). Another reason for selecting this time-point was that osteoblast differentiation was induced in 13 days in the in vitro experiments of the present study.

Differential analysis for miRNAs and mRNAs. The reads data of GSE107279 (12) and GSE112318 (13) were downloaded from the GEO repository and mean-normalized. The differentially expressed miRNAs (DEMs) and genes (DEGs) between differentiated and undifferentiated samples were identified using DESeq2 (http://www.bioconductor. org/packages/release/bioc/html/DESeq2.html.). package (14) in $R(15)$. |log2fold change (FC) $\mid>0.5$ and false discovery rate (FDR)-adjusted $\mathrm{P}<0.05$ represented the statistical threshold for DEMs and DEGs. A heat map was created using the 'pheatmap' package (version: 1.0.8; https://cran.r-project. org/web/packages/pheatmap) based on the Euclidean distance.

Target gene prediction for miR-128-3p. The BLAST server (blast.ncbi.nlm.nih.gov/Blast.cgi) was used to identify the nucleotide sequence similarity of human and rat miR-128-3p. The target genes of miR-128-3p were predicted using the miRwalk database (version 2.0; zmf.umm.uni-heidelberg. de/apps/zmf/mirwalk2) (16). The miRwalk database included 12 algorithms and the genes that were predicted in at least 5 databases were collected. A Venn diagram (http://bioinformatics.psb.ugent.be/webtools/Venn/) was drawn to screen the common genes predicted using the human and rat as the species parameters (since rat BM-MSCs were used in validation experiments) in miRwalk database and the shared genes between predicted genes and DEGs, which were considered to be possibly crucial targets of miR-128-3p. The miRNA-mRNA regulatory network was visualized using the Cytoscape software (version 3.4; www.cytoscape.org/) (17).

Protein-protein interaction (PPI) network. The interactions between two target genes of miR-128-3p were predicted using the STRING (Search Tool for the Retrieval of Interacting Genes; version 10.0; http://string db.org/) database (18), with the relationship pairs having a combined score $>0.4$ being used to construct the PPI network. Several topological features of the nodes (proteins) in the PPI network were calculated using the CytoNCA plugin in the Cytoscape software (http://apps.cytoscape.org/apps/cytonca) (19) to screen hub genes, including degree centrality (DC), eigenvector centrality (EC) and closeness centrality (CC). In addition, several function-related modules were also extracted from the PPI network using the Molecular Complex Detection (MCODE; version, 1.4.2; http://apps.cytoscape.org/apps/mcode) plugin of the Cytoscape software.

Function enrichment analysis for target genes of miR-128-3p. Kyoto Encyclopedia of Genes and Genomes (KEGG; version Release 92.0, October 1, 2019; genome.jp/kegg/) pathway enrichment analysis was performed for target genes of DEMs using the enricher tool (https://amp.pharm.mssm. edu/Enrichr/) (20). FDR $<0.05$ was considered to be statistically significant.

Function validation of miR-128-3p for the osteoblast differentiation from BM-MSCs. BM-MSCs of Wistar rats were purchased from the Chinese Academy of Science Cell Bank and cultured in Alpha Minimum Essential Medium ( $\alpha$-MEM; Gibco, Thermo Fisher Scientific, Inc.) supplemented with GlutaMAX ${ }^{\mathrm{TM}}-\mathrm{I}, 10 \%$ fetal bovine serum and $1 \%$ penicillin/streptomycin (all Gibco; Thermo Fisher Scientific, Inc.) at $37^{\circ} \mathrm{C}$ in a humidified atmosphere of $5 \% \mathrm{CO}_{2}$ in air. 
Transfection. miR-128-3p mimics and miR-normal control (miR-NC) were obtained from Shanghai GenePharma Co., Ltd. On the day before the transient transfections, the cells were seeded into 6 -well plates and incubated $\left(37^{\circ} \mathrm{C}\right)$ to reach $65 \%$ confluency. Then, $\operatorname{miR}-128-3 p$ mimics $(15,30$, 40 and $50 \mathrm{pmol})$ and the scrambled control were transfected into BM-MSCs of Wistar rats using Lipofectamine ${ }^{\circledR} 2000$ (Invitrogen; Thermo Fisher Scientific, Inc.) according to the manufacturer's protocol.

After $48 \mathrm{~h}$ of transfection, the cells were collected to detect proliferation ability and the expression of miR-128-3p, in order to screen the optimal treatment concentration of miR-128-3p mimics. Subsequently, the cells were treated with this concentration of miR-128-3p mimics for 13 days to observe its functions on the osteoblast differentiation and the expression of target genes.

Cell proliferation. Cell proliferation ability of BM-MSCs was determined using Cell Counting Kit-8 (CCK-8; Dojindo Molecular Technologies, Inc.). Briefly, cells were seeded into a 96 -well plate at a density of $2 \times 10^{3} /$ well and cultured at $37^{\circ} \mathrm{C}$, $5 \% \mathrm{CO}_{2}$. Then, $10 \mu \mathrm{l}$ of CCK-8 solution was added to assay the cell growth status. At $2 \mathrm{~h}$ following CCK-8 treatment, the absorbance of each well at $450 \mathrm{~nm}$ wavelengths was measured by a microplate reader.

Reverse transcription-quantitative $(R T-q) P C R$. RT-qPCR was used for the analysis of gene expression according to the manufacturer's protocols. Briefly, total RNA was extracted from $2 \times 10^{3}$ cells using TRIzol ${ }^{\circledR}$ reagent (Thermo Fisher Scientific, Inc.). The high-purity and intact RNA (OD260/OD280>1.9) was converted into cDNA by the GoScript Reverse Transcription System (Promega Corporation). RT-qPCR was then performed on a CFX96 Real-Time System/C1000 Thermal Cycler (Bio-Rad Laboratories, Inc.) using AceQ ${ }^{\circledR}$ RT-qPCR SYBR-Green Master Mix (Vazyme Biotech Co., Ltd.). The reaction conditions for RT-qPCR were pre-incubation at $95^{\circ} \mathrm{C}$ for $10 \mathrm{~min}$, followed by amplification with 39 cycles of $10 \mathrm{sec}$ denaturation at $95^{\circ} \mathrm{C}, 20 \mathrm{sec}$ annealing at $65^{\circ} \mathrm{C}$ and $10 \mathrm{sec}$ elongation at $72^{\circ} \mathrm{C}$. U6 and actin were used as the internal reference for miRNA and mRNA detection, respectively. Relative expression levels were analyzed using the $2^{-\Delta \Delta \mathrm{Cq}}$ method (21). The primers used are listed in Table I.

Osteogenic differentiation. Osteogenic differentiation of BM-MSCs was induced using standard osteogenic medium consisting of phenol red-free $\alpha$-MEM, $10 \%$ FBS, ascorbic acid $(50 \mu \mathrm{g} / \mathrm{ml})$, dexamethasone $\left(10^{-8} \mathrm{M}\right)$ and $\beta$-glycerophosphate $\left(10^{-2} \mathrm{M}\right)$. The medium was changed twice every week. The osteoblastic differentiation potency of BM-MSCs was determined by Alizarin red staining: After induction culture for 2 weeks, the cells were washed with PBS and fixed with 4\% paraformaldehyde for $10 \mathrm{~min}$ and then stained using $2 \%$ Alizarin red for $20 \mathrm{~min}$ at room temperature to evaluate calcium nodule formation.

Statistical analysis. All experiments were performed for at least three biological repeats. Statistical analysis was performed using SPSS 18.0 (SPSS, Inc.) and graphs were prepared in GraphPad Prism 5.0 (GraphPad Software, Inc.).
Table I. Primers used in the present study.

\begin{tabular}{|c|c|}
\hline Gene & Primer sequence $\left(5^{\prime}-3^{\prime}\right)$ \\
\hline ACTIN & $\begin{array}{l}\text { F: GAGACCTTCAACACCCCAGC } \\
\text { R: ATGTCACGCACGATTTCCC }\end{array}$ \\
\hline$R U N X 1$-rat & $\begin{array}{l}\text { F: GGTTTCGCAGCGTGGTAAAA } \\
\text { R: GCACTGTGGGTACGAAGGAA }\end{array}$ \\
\hline$K I T$-rat & $\begin{array}{l}\text { F: TACTTGGAGCCTGCACCATT } \\
\text { R: TATCGCTGCAGGAAGACTCC }\end{array}$ \\
\hline AXIN1-rat & $\begin{array}{l}\text { F: GTGCCCCTACCTCACATTCC } \\
\text { R: CTCACCTTCCTCCTCCATGC }\end{array}$ \\
\hline$Y W H A B$-rat & $\begin{array}{l}\text { F: GTCTCCAGAGATTTGGGCCG } \\
\text { R: CCATTGTCATTCCCTGACTCCA }\end{array}$ \\
\hline$G A B 1$-rat & $\begin{array}{l}\text { F: GAGAGCTAGGTTCTCGCCAC } \\
\text { R: TCCTCTTCCATGCATAACGCT }\end{array}$ \\
\hline NTRK2-rat & $\begin{array}{l}\text { F: TTACGGTTTGTCACCCGACC } \\
\text { R: GTGCTTGGTTCAGCTCTTGC }\end{array}$ \\
\hline RUNX2-rat & $\begin{array}{l}\text { F: GCCAATCCCTGAGTGTGACT } \\
\text { R: CCTGGTGGTGTCACTGAATG }\end{array}$ \\
\hline$B G L A P$-rat & $\begin{array}{l}\text { F: CACCGTTTAGGGCATGTGTT } \\
\text { R: TCCTGGAGAGTAGCCAAAGC }\end{array}$ \\
\hline miR-128-3p-rat & $\begin{array}{l}\text { F: CGCGTCACAGTGAACCGGT } \\
\text { R: AGTGCAGGGTCCGAGGTATT }\end{array}$ \\
\hline U6 & AACGCTTCACGAATTTGCGT \\
\hline
\end{tabular}

F, forward; R, reverse; miR, microRNA.

All data were expressed as the mean \pm standard deviation. Statistical differences between two groups were determined using two-tailed paired Student's t-test; while statistical comparisons among more than two groups were performed using one-way ANOVA followed by post hoc Tukey's test. $\mathrm{P}<0.05$ was considered to indicate a statistically significant difference.

\section{Results}

Identification of miR-128 as a DEM in osteoblast-differentiated BM-MSCs. Among the $654 \mathrm{miRNAs}$ included in the GSE107279 dataset, 338 of them were found to be differentially expressed between differentiated and undifferentiated BM-MSCs under the stated threshold, including 295 downregulated and 43 upregulated DEMs (Fig. 1A and B). miR-128 was one of the significantly downregulated DEMs in differentiated BM-MSCs, with a $\log 2 \mathrm{FC}$ of -0.77 and an FDR-adjusted $\mathrm{P}$-value of $1.93 \times 10^{-12}$.

Identification of the crucial target genes of miR-128 for osteoblast-differentiated BM-MSCs. Among the 19,652 genes included in the GSE112318 dataset, 14,894 of them were revealed to be differentially expressed between differentiated and undifferentiated BM-MSCs under the stated threshold, including 9,571 downregulated and 5,323 upregulated DEGs (Fig. 1C and D). 
Table II. Topological properties of genes in the PPI network.

\begin{tabular}{|c|c|c|c|c|c|c|c|c|}
\hline \multirow[b]{2}{*}{ Gene } & \multirow[b]{2}{*}{$\mathrm{DC}$} & \multirow[b]{2}{*}{ Gene } & \multirow[b]{2}{*}{$\mathrm{CC}$} & \multirow[b]{2}{*}{ Gene } & \multirow[b]{2}{*}{$\mathrm{EC}$} & \multirow[b]{2}{*}{ Common } & \multicolumn{2}{|c|}{ Expression } \\
\hline & & & & & & & $\log \mathrm{FC}$ & FDR \\
\hline$E G F R$ & 39 & $E G F R$ & 0.068059 & $E G F R$ & 0.39794025 & $T G O L \mathrm{~N} 2$ & -1.08 & 0 \\
\hline IL6 & 32 & IL6 & 0.067039 & IL6 & 0.34596485 & $K I T$ & 1.88 & $2.43 \times 10^{-209}$ \\
\hline$A R$ & 22 & $A R$ & 0.066937 & $A R$ & 0.23498377 & PPPICC & -0.64 & 0 \\
\hline$A B L 1$ & 18 & IRSI & 0.066785 & IRSI & 0.2286748 & FURIN & -2.45 & 0 \\
\hline PPPICC & 18 & $A B L 1$ & 0.066667 & $A B L 1$ & 0.20841703 & PPP4C & -1.00 & 0 \\
\hline IRSI & 17 & MAPK14 & 0.066348 & CXCL12 & 0.19866262 & CANX & -0.55 & 0 \\
\hline CXCL12 & 16 & $Y W H A B$ & 0.066265 & $K I T$ & 0.18829939 & $E G F R$ & -1.68 & 0 \\
\hline$K I T$ & 14 & TGFBRI & 0.066033 & MAPK14 & 0.1772947 & NTRK2 & 4.77 & 0 \\
\hline$P X N$ & 14 & $P P P 1 C C$ & 0.065885 & $P X N$ & 0.16721927 & $C X C L 1$ & -3.06 & 0 \\
\hline CANX & 14 & $P P P 2 R 1 B$ & 0.065852 & $G A B 1$ & 0.1594914 & TGFBRI & -0.79 & 0 \\
\hline МAPK14 & 12 & $P X N$ & 0.06577 & NANOG & 0.14420108 & IRS1 & -0.96 & 0 \\
\hline$A D C Y 3$ & 12 & PPP $4 C$ & 0.065753 & CXCL1 & 0.14116184 & $P P P 2 R 1 B$ & -2.08 & 0 \\
\hline$A D C Y 6$ & 12 & $N A N O G$ & 0.065737 & $R E T$ & 0.1360971 & MAPK14 & -0.69 & 0 \\
\hline$T G F B R 1$ & 11 & CXCL12 & 0.065721 & $T G F B R 1$ & 0.12943284 & $A T P 2 A 2$ & -2.00 & 0 \\
\hline$Y W H A B$ & 11 & $K I T$ & 0.065606 & CANX & 0.12310072 & $A B L 1$ & -1.99 & 0 \\
\hline GNB2 & 11 & $C A N X$ & 0.065557 & $K L F 4$ & 0.12178243 & $Y W H A B$ & 0.51 & 0 \\
\hline CXCLI & 10 & AXIN1 & 0.065557 & NTRK2 & 0.116883084 & $G A B 1$ & 0.53 & $6.04 \times 10^{-81}$ \\
\hline$N T R K 2$ & 10 & $Y W H A Q$ & 0.06546 & $Y W H A B$ & 0.112461776 & $N A N O G$ & -2.66 & $2.03 \times 10^{-51}$ \\
\hline$G A B B R 2$ & 10 & $O C L N$ & 0.065379 & $I L 6 R$ & 0.11212979 & CXCL12 & -9.14 & 0 \\
\hline$P P P 2 R 1 B$ & 10 & SMURF 1 & 0.06525 & $O C L N$ & 0.11207541 & $A X I N 1$ & 0.78 & $4.50 \times 10^{-27}$ \\
\hline AXIN1 & 10 & NTRK2 & 0.065234 & GRB10 & 0.10549404 & $A R$ & -1.01 & 0 \\
\hline SMURF1 & 10 & $K L F 4$ & 0.065169 & PPPICC & 0.09967908 & $R E T$ & -10.3 & $6.15 \times 10^{-99}$ \\
\hline$G A B 1$ & 9 & $C X C L 1$ & 0.065137 & $C X C L 2$ & 0.098889045 & IL6 & -1.15 & 0 \\
\hline$N A N O G$ & 9 & $A T P 2 A 2$ & 0.065105 & TGOLN2 & 0.09819438 & $R U N X 1$ & 0.71 & 0 \\
\hline$O C L N$ & 9 & TGOLN2 & 0.065057 & ATG5 & 0.0979064 & $O C L N$ & -10.2 & $1.76 \times 10^{-94}$ \\
\hline PPP4C & 9 & $G A B 1$ & 0.065009 & $G N B 2$ & 0.093786895 & $P X N$ & -0.97 & 0 \\
\hline KMT2A & 9 & DYNC1LI2 & 0.064993 & TIMP3 & 0.09199475 & & & \\
\hline GYS1 & 9 & $R U N X 1$ & 0.064977 & $I T G A 5$ & 0.09169616 & & & \\
\hline$R U V B L 2$ & 9 & ATG5 & 0.064929 & $I T P K C$ & 0.08899418 & & & \\
\hline$R E T$ & 8 & GYS1 & 0.064897 & $G A B B R 2$ & 0.08424522 & & & \\
\hline CXCL2 & 8 & $R D X$ & 0.064865 & $R U N X 1$ & 0.08272818 & & & \\
\hline TGOLN2 & 8 & $R E T$ & 0.064865 & $P P P 2 R 1 B$ & 0.08233988 & & & \\
\hline$G A B B R 1$ & 8 & FURIN & 0.064833 & $A D C Y 3$ & 0.08222689 & & & \\
\hline FURIN & 8 & $I T P K C$ & 0.064769 & $A D C Y 6$ & 0.08222689 & & & \\
\hline$A T P 2 A 2$ & 8 & $K M T 2 A$ & 0.064753 & $Y W H A Q$ & 0.082175 & & & \\
\hline DYNC1LI2 & 8 & GRB10 & 0.064753 & $P P P 4 C$ & 0.08180887 & & & \\
\hline$P Y G B$ & 8 & TIMP3 & 0.064722 & AXIN1 & 0.080903396 & & & \\
\hline BET1L & 8 & SEC61A1 & 0.06469 & FURIN & 0.07912381 & & & \\
\hline$R U N X 1$ & 7 & $P H B$ & 0.064674 & $A T P 2 A 2$ & 0.07898864 & & & \\
\hline CACNB2 & 7 & $I L 6 R$ & 0.064643 & ITIH4 & 0.07645497 & & & \\
\hline
\end{tabular}

DC, degree centrality; EC, eigenvector centrality; CC, closeness centrality; PPI, protein-protein interaction; FC, fold change; FDR, false discovery rate.

The sequence of has-miR-128-3p and Rno-miR-128-3p was $100 \%$ identical (Fig. 2A). Thus, the targets of miR-128-3p were predicted using human and rat as species, respectively. Using the miRwalk 2.0 database, 4,443 target genes were 
A

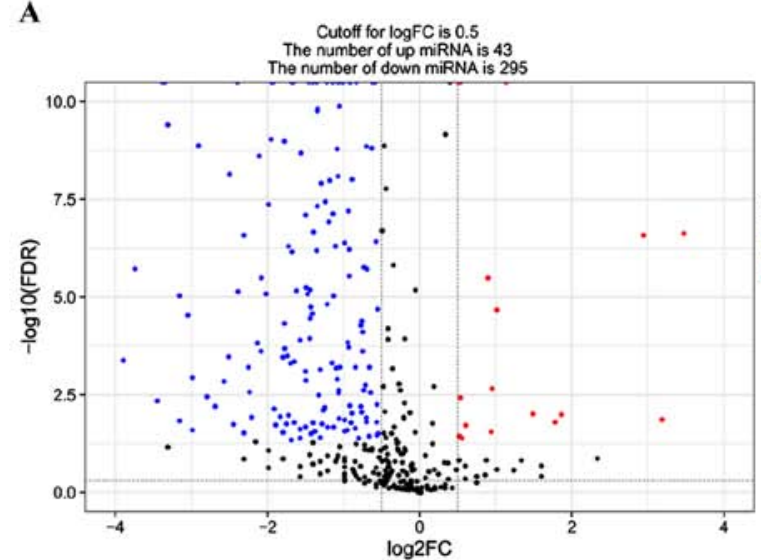

C

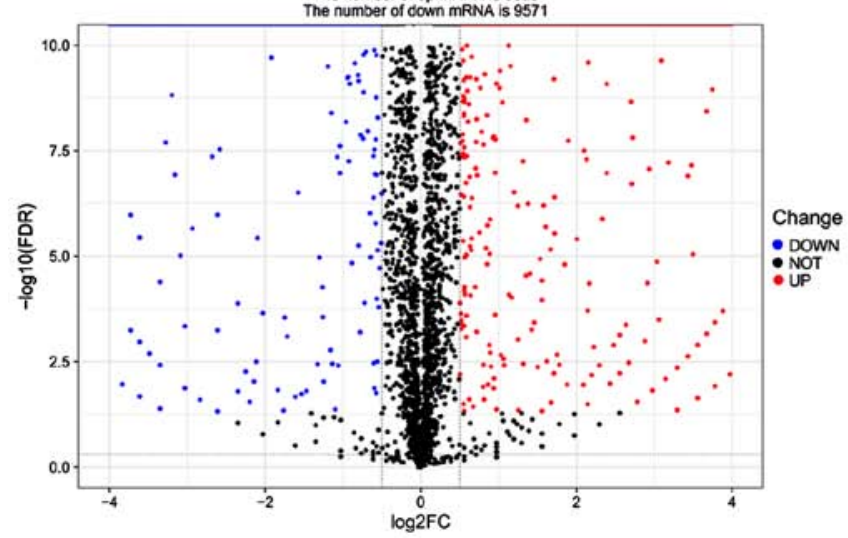

B

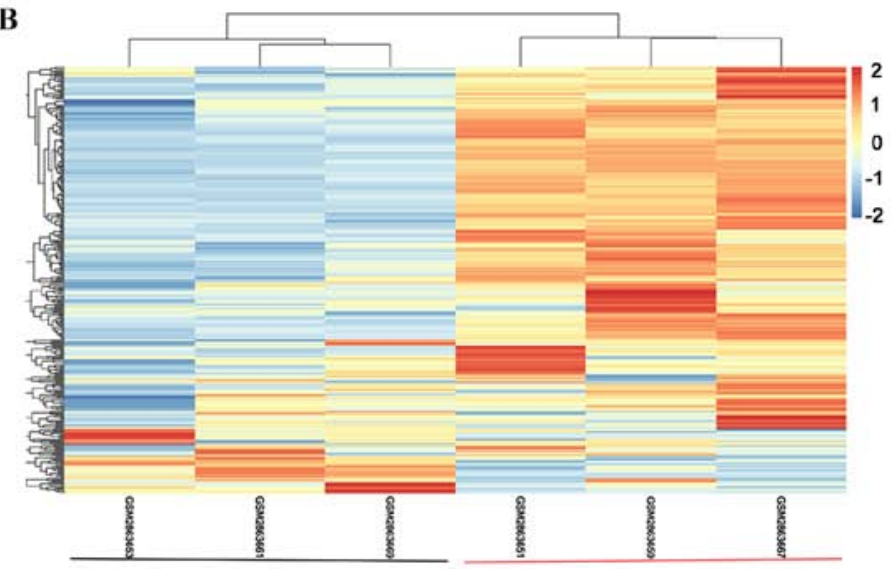

D

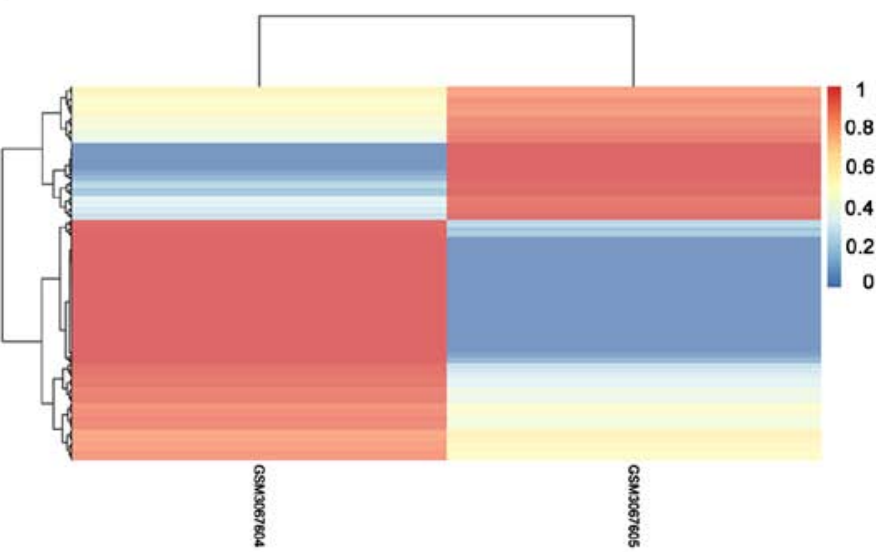

Figure 1. (A and C) Volcano plot and (B and D) heat maps of differentially expressed miRNAs and mRNAs between differentiated and undifferentiated BM-MSCs. (A and B) miRNA sequencing datasets of GSE107279; (C and D) mRNA sequencing datasets of GSE112318. Colors shading to red; high expression; colors shading to light blue, low expression. Intensity of color reflects degree of expression. miRNA, microRNA; BM-MSCs, bone marrow-derived mesenchymal stem cells.

predicted to interact with human miR-128-3p in the 3 'UTR, while 1,331 were predicted to be regulated by rat miR-128-3p via the 3'UTR. Among them, 582 were shared between the two species (Fig. 2B). Furthermore, 332 of 582 genes were overlapped with the DEGs (Fig. 2C), including 103 upregulated and 229 downregulated (which were used for establishing the miRNA-mRNA network, as shown in Fig. 3), suggesting these 103 upregulated DEGs may be underlying target genes of downregulated miR-128-3p.

In order to further screen crucial targets for miR-128-3p, the PPI network and function modules were analyzed. A total of 264 DEGs were identified to interact with other genes to form 539 interaction pairs (such as NTRK2-GAB1, GAB1-IRS1, YWHAB-PPPICC, AXIN1-GYS1 and GYS1-IRS1, which was used for constructing the PPI network. After calculating the topological properties, 26 DEGs (including 6 upregulated: $K I T, N T R K 2, Y W H A B, G A B 1, A X I N 1$ and $R U N X 1)$ were found to be shared in the top 40 genes ranking for DC, CC and EC (Table II). In addition, 11 modules were extracted from the PPI network. Among them, only module 4 (RUNX1, KIT, $G A B 1$ and $A X I N 1$; in which $R U N X 1$ may be especially key since it could interact with $K I T$ and $A X I N 1)$ and module 7 $(Y W H A B)$ included the shared upregulated DEGs identified by topological ranking (Fig. 4; Table III). These findings indicated that these 5 upregulated genes may be particularly crucial targets of miR-128-3p.
Function enrichment analysis of the genes in the PPI network revealed that $30 \mathrm{KEGG}$ pathways were enriched, including Insulin resistance (PPPICC and IRS1), Hippo signaling pathway (PPPICC, $Y W H A B$ and $A X I N 1)$, Pathways in cancer (RUNX1, AXIN1 and KIT), PI3K-Akt signaling pathway ( $Y W H A B, K I T$ and $N T R K 2)$, Tight junction (RUNX1), Proteoglycans in cancer $(G A B I)$ and Rap1 signaling pathway (KIT) (Table IV).

Validation of the function on the osteoblast differentiation of miR-128-3p and the expression of target genes. To confirm the differential characteristics of miR-128-3p and their target genes during the osteoblast differentiation, RT-qPCR was performed. As anticipated, the results demonstrated that osteogenic induction can lead to a reduction in the expression of miR-128-3p and an increase in the expression of its potential target genes (KIT, NTRK2, YWHAB, GAB1, AXIN1 and RUNX1; Fig. 5A).

To further validate the regulatory relationship between miR-128-3p and its target genes, miR-128-3p mimic transfection experiments were carried out. After transfection of miR-128-3p into rat BM-MSCs for $48 \mathrm{~h}$, the expression of miR-128-3p (Fig. 5B) and the cell proliferation (Fig. 5C) of BM-MSCs were revealed to be the highest in the group with the treatment concentration of $50 \mathrm{pmol}$, indicating the successful overexpression of miR-128-3p. Thus, this 


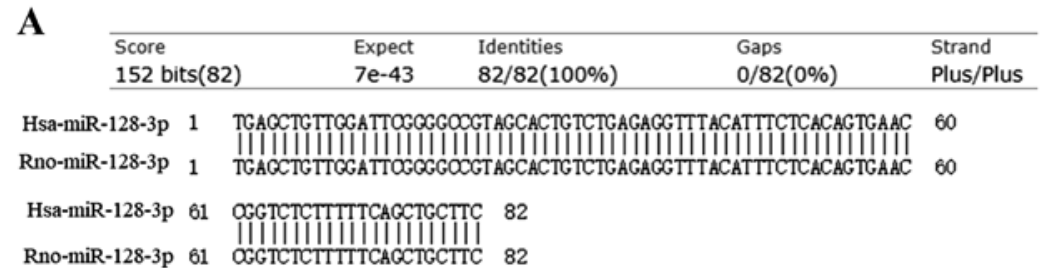

B

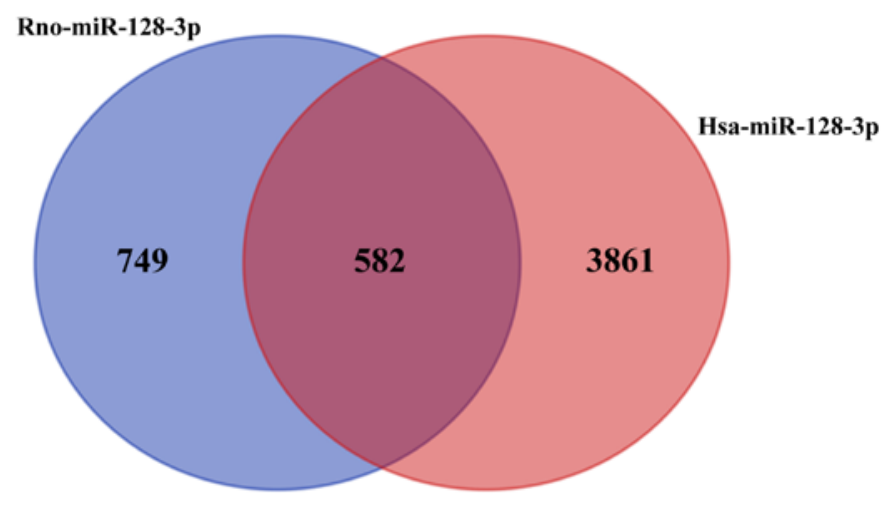

C Common target genes

Differentially expressed genes

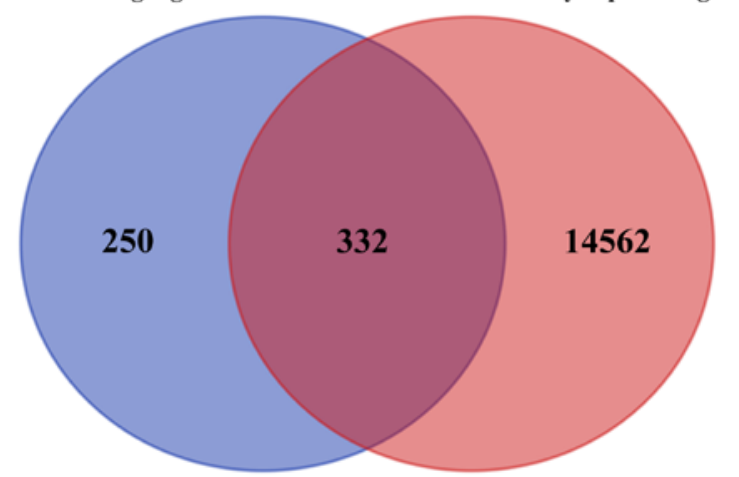

Figure 2. Identification of target genes of miR-128. (A) The BLAST results of human and rat miR-128-3p. (B) Venn diagram to screen the common genes regulated by human and rat miR-128-3p. (C) Venn diagram of predicted target genes of miR-128-3p and differentially expressed genes shared by differentiated and undifferentiated BM-MSCs. miRNA, microRNA; BM-MSCs, bone marrow-derived mesenchymal stem cells; Has, human; Rno, rat.

Table III. Modules extracted from the PPI network.

\begin{tabular}{lcccl}
\hline Cluster & $\begin{array}{c}\text { Score (density } \mathrm{x} \\
\text { number of nodes) }\end{array}$ & Nodes & Edges & \multicolumn{1}{c}{ Node IDs } \\
\hline 1 & 8 & 8 & 28 & $\begin{array}{l}\text { CXCL12, GABBR2, GABBR1, ADCY3, CXCL1, CXCL2, GNB2, } \\
\text { ADCY6 }\end{array}$ \\
2 & 5.2 & 11 & 26 & $\begin{array}{l}\text { PXN, AR, IL6R, TGFBR1, IL6, EGFR, RET, ABL1, NANOG, OCLN, } \\
\text { KLF4 }\end{array}$ \\
3 & 4 & 4 & 6 & $\begin{array}{l}\text { TRMT61A, WDR43, RRP8, MAK16 } \\
\text { GAB1, KIT, PPME1, RUNX1, PYGB, AGL, AXIN1, ITPKC, PPP4C, }\end{array}$ \\
5 & 3.538 & 14 & 23 & TIPRL, PPP1R3B, GYS1, IRS1, PFKM \\
5 & 3 & 3 & 3 & STMN2, FAIM2, CNTN2 \\
6 & 3 & 3 & 3 & BET1L, SEC22A, STX7 \\
7 & 3 & 5 & 6 & YWHAB, PAPD7, PPP2R1B, RUVBL2, PPP1CC \\
8 & 3 & 3 & 3 & FAM160B1, IGSF3, POGLUT1 \\
9 & 3 & 3 & 3 & RHOT2, ARHGAP28, DEPDC1B \\
10 & 3 & 3 & 3 & ANO6, ATP11A, CD47 \\
11 & 3 & 3 & 3 & SGMS1, SMPD3, UGCG \\
\hline
\end{tabular}

PPI, protein-protein interaction. 


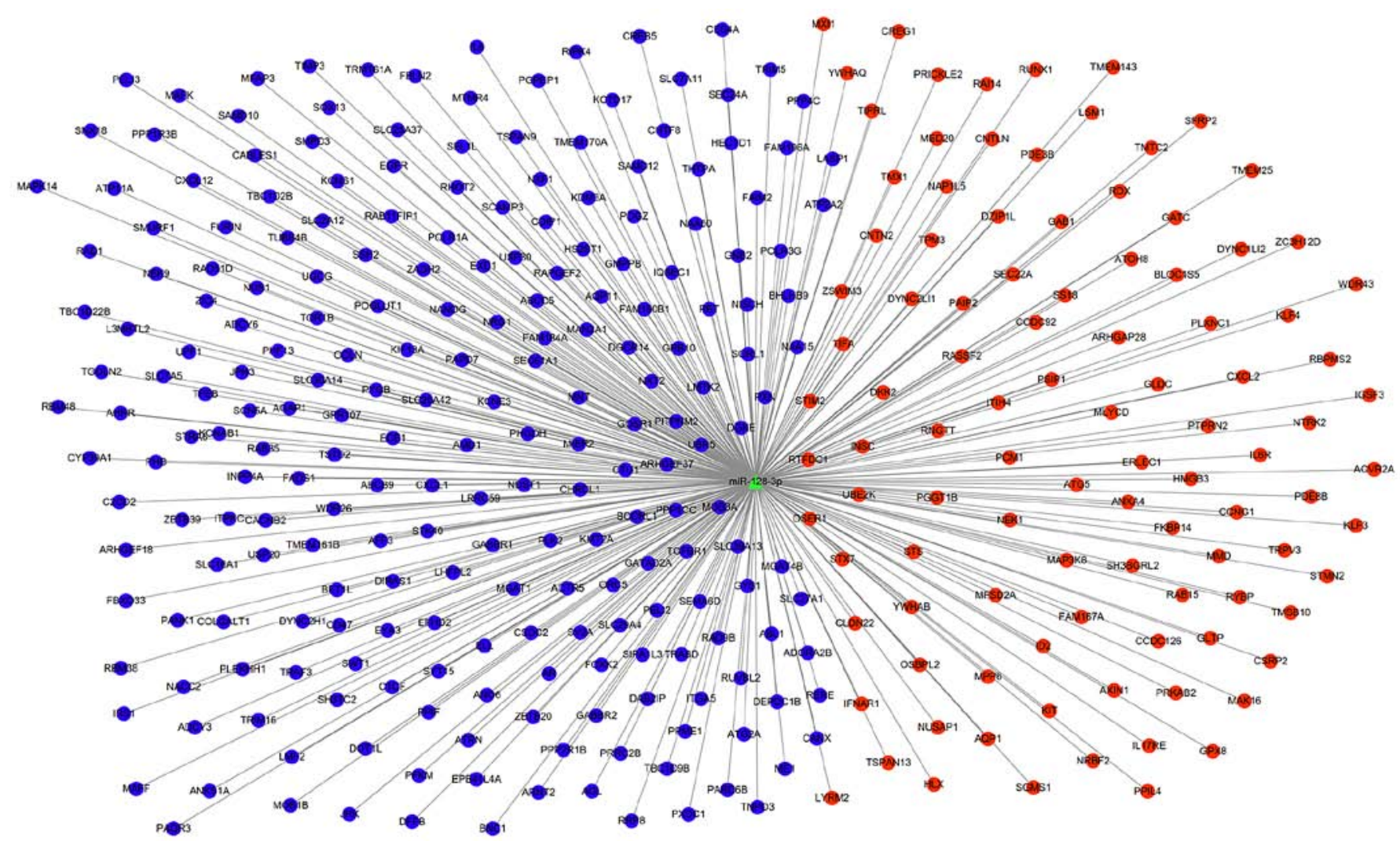

Figure 3. miR-128-3p-mRNA regulatory network. Red, upregulated differentially expressed mRNAs; blue, downregulated differentially expressed mRNAs. miRNA, microRNA.

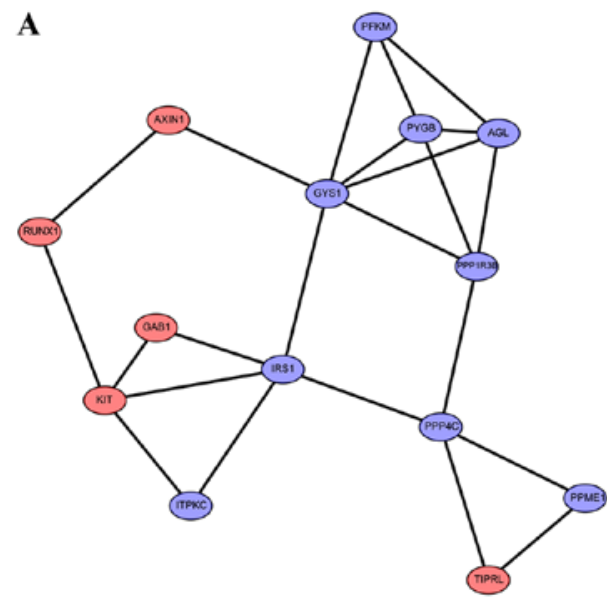

B

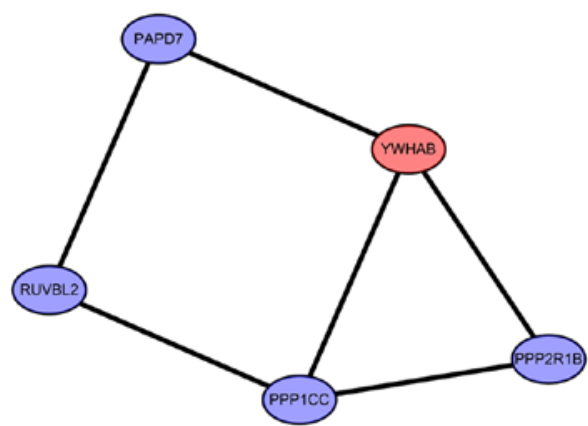

Figure 4. Protein-protein interaction modules including the hub target genes of miR-128-3p. (A) Module 4; (B) module 7. Red, upregulated differentially expressed mRNAs; blue, downregulated differentially expressed mRNAs. miRNA, microRNA.

concentration was used to investigate the influence of miR-128-3p overexpression on the osteoblast differentiation of BM-MSCs. In line with the sequencing data analysis results and our previous study on human BM-MSCs (11), overexpression of miR-128-3p clearly decreased calcium deposition (Fig. 5D) and significantly weakened the expression levels of osteogenic specific markers Runx2 (22) and bone $\gamma$-carboxyglutamate protein (BGLAP) (23) (Fig. 5E), further suggesting its inhibitory effects on the osteoblast differentiation. Notably, the expression levels of 6 target genes as aforementioned were significantly decreased in the miR-128-3p-mimics group compared with the miR-NC group (Fig. 5E).

\section{Discussion}

The present study, using an integrated analysis of miRNA and mRNA sequencing datasets and in vitro verification, revealed that miR-128-3p may inhibit the osteoblast differentiation of BM-MSCs by targeted downregulation of RUNX1,NTRK2 and $Y W H A B$. Subsequently, these target genes may respectively regulate the expression of downstream $A X I N 1, K I T, G A B 1$ and 
Table IV. KEGG pathways enriched for the genes in the PPI network.

\begin{tabular}{|c|c|c|}
\hline Term & P-value & Genes \\
\hline Insulin resistance & $4.22 \times 10^{-3}$ & $\begin{array}{l}\text { PPP1CC, PYGB, GYS1, SLC27A1, PRKAB2, IL6, IRS1, PPPIR3B, } \\
\text { CREB5 }\end{array}$ \\
\hline Vasopressin-regulated water reabsorption & $3.64 \times 10^{-3}$ & DYNC2LI1, DYNC2H1, DYNC1LI2, ADCY3, ADCY6, CREB5 \\
\hline Adrenergic signaling in cardiomyocytes & $2.48 \times 10^{-3}$ & $\begin{array}{l}P P P 1 C C, C A C N B 2, P P P 2 R 1 B, T P M 3, A T P 2 A 2, A D C Y 3, S C N 5 A, \\
M A P K 14, A D C Y 6, C R E B 5\end{array}$ \\
\hline Hippo signaling pathway & $4.32 \times 10^{-3}$ & $\begin{array}{l}\text { MOB1B, PPP1CC, PARD6B, RASSF2, PPP } 2 R 1 B, Y W H A Q, \\
Y W H A B, I D 2, A X I N 1, T G F B R 1\end{array}$ \\
\hline TNF signaling pathway & $6.73 \times 10^{-3}$ & $\begin{array}{l}\text { IL6, TRAF3, DAB2IP, MAP3K8, CXCL1, MAPK14, CXCL2, } \\
\text { CREB5 }\end{array}$ \\
\hline Morphine addiction & $1.07 \times 10^{-2}$ & GABBR2, GABBR1, GNB2, PDE3B, ADCY3, PDE8B, ADCY6 \\
\hline Pathways in cancer & $1.18 \times 10^{-2}$ & $\begin{array}{l}\text { RET }, A R N T 2, T P M 3, A X I N 1, A D C Y 3, A D C Y 6, E G F R, T G F B R 1, \\
R U N X 1, A R, I L 6, C X C L 12, T R A F 3, G N B 2, K I T, A B L 1, I L 6 R, \\
\text { IFNAR1 }\end{array}$ \\
\hline PI3K-Akt signaling pathway & $1.10 \times 10^{-2}$ & $\begin{array}{l}\text { NTRK2 IRS1, YWHAB, EGFR, GYS1,IL6, PPP2R1B, YWHAQ, } \\
\text { GNB2, KIT, ITGA5, IL6R, IFNAR1, CREB5 }\end{array}$ \\
\hline Tight junction & $1.55 \times 10^{-2}$ & $\begin{array}{l}C L D N 22, P R K A B 2, O C L N, P A R D 6 B, P P P 2 R 1 B, R D X \\
A R H G E F 18, R A P G E F 2, R U N X 1\end{array}$ \\
\hline Human cytomegalovirus infection & $2.69 \times 10^{-2}$ & $\begin{array}{l}\text { IL6, CXCL12, GNB2, PXN, ADCY3, MAPK14,IL6R, ADCY6, } \\
\text { EGFR, CREB5 }\end{array}$ \\
\hline Hypertrophic cardiomyopathy & $2.61 \times 10^{-2}$ & CACNB2, PRKAB2, IL6, TPM3, ATP2A2, ITGA5 \\
\hline Salmonella infection & $2.55 \times 10^{-2}$ & DYNC2H1, DYNC1LI2, IL6, CXCL1, MAPK14, CXCL2 \\
\hline Hepatitis C & $2.61 \times 10^{-2}$ & $\begin{array}{l}\text { CLDN22, OCLN, PPP2RIB, YWHAQ, YWHAB, TRAF3, EGFR, } \\
\text { IFNAR1 }\end{array}$ \\
\hline AMPK signaling pathway & $2.43 \times 10^{-2}$ & GYS1, PRKAB2, PPP2R1B, IRS1, MLYCD, PFKM, CREB5 \\
\hline Dilated cardiomyopathy & $2.73 \times 10^{-2}$ & CACNB2, TPM3, ATP2A2, ADCY3, ITGA5, ADCY6 \\
\hline mRNA surveillance pathway & $2.56 \times 10^{-2}$ & $P P P 1 C C, U P F 1, N X F 1, R N G T T, P P P 2 R 1 B, N X T 2$ \\
\hline Oocyte meiosis & $2.54 \times 10^{-2}$ & PPPICC , AR, PPP2RIB, YWHAQ, YWHAB, ADCY3, ADCY6 \\
\hline Proteoglycans in cancer & $2.55 \times 10^{-2}$ & $\begin{array}{l}P P P 1 C C, R D X, P X N, G A B 1, T I M P 3, N A N O G, I T G A 5, M A P K 14, \\
\text { EGFR }\end{array}$ \\
\hline Hepatitis B & $2.46 \times 10^{-2}$ & $\begin{array}{l}\text { IL6, YWHAQ, YWHAB, TRAF3, MAPK14, TGFBR1, IFNAR1, } \\
\text { CREB5 }\end{array}$ \\
\hline Central carbon metabolism in cancer & $2.62 \times 10^{-2}$ & RET, SLC7A5, KIT, PFKM, EGFR \\
\hline cGMP-PKG signaling pathway & $2.50 \times 10^{-2}$ & PPP1CC, IRS1, PDE3B, PPIF, ATP2A2, ADCY3, ADCY6, CREB5 \\
\hline Relaxin signaling pathway & $2.46 \times 10^{-2}$ & GNB2, ADCY3, MAPK14, TGFBR1, EGFR, ADCY6, CREB5 \\
\hline Rap1 signaling pathway & $2.36 \times 10^{-2}$ & $\begin{array}{l}\text { PARD6B, ADORA2B, KIT, RAPGEF2, ADCY3, MAPK14, } \\
\text { SIPA1L3, ADCY6,EGFR }\end{array}$ \\
\hline FoxO signaling pathway & $2.46 \times 10^{-2}$ & PRKAB2, IL6, IRS1, PLK2, MAPK14, TGFBR1, EGFR \\
\hline Insulin signaling pathway & $2.91 \times 10^{-2}$ & PPP1CC, PYGB, GYS1, PRKAB2, IRS1, PPP1R3B, PDE3B \\
\hline Longevity regulating pathway & $2.82 \times 10^{-2}$ & PRKAB2, IRS1, ADCY3, ADCY6, ATG5, CREB5 \\
\hline Glucagon signaling pathway & $2.86 \times 10^{-2}$ & $P Y G B, G Y S 1, P R K A B 2, P P P 4 C, P D E 3 B, C R E B 5$ \\
\hline Thyroid hormone synthesis & $3.31 \times 10^{-2}$ & $C A N X, G P X 8, A D C Y 3, A D C Y 6, C R E B 5$ \\
\hline Phagosome & $4.47 \times 10^{-2}$ & DYNC2H1, SEC61A1, DYNC1LI2, STX7, CANX, ITGA5, TUBB4B \\
\hline Cushing syndrome & $4.80 \times 10^{-2}$ & KMT2A, AXIN1, ADCY3, PDE8B, EGFR, ADCY6, CREB5 \\
\hline
\end{tabular}

KEGG, Kyoto Encyclopedia of Genes and Genomes; PPI, protein-protein interaction; TNF, tumor necrosis factor; AMPK 5' AMP-activated protein kinase; cGMP, cyclic GMP; PKG, protein kinase G; Rap1, Ras-proximate-1; FOX, forkhead box.

PPPICC to mediate Insulin resistance, Hippo, PI3K-Akt and Rap1 signaling pathways.

There is evidence that RUNX1 plays an important role in mediating the osteogenic differentiation of stem cells and this was associated with miR-128 (24). For example,
Luo et al (25) revealed that knockdown of RUNX1 in murine BM-MSCs significantly inhibited osteogenesis (as evaluated by lower ALP activity and reduced calcium nodule formation) and decreased the expression levels of osteogenic-related genes ( $R U N X 2, O C N$ and $O P N)$ compared with 
A
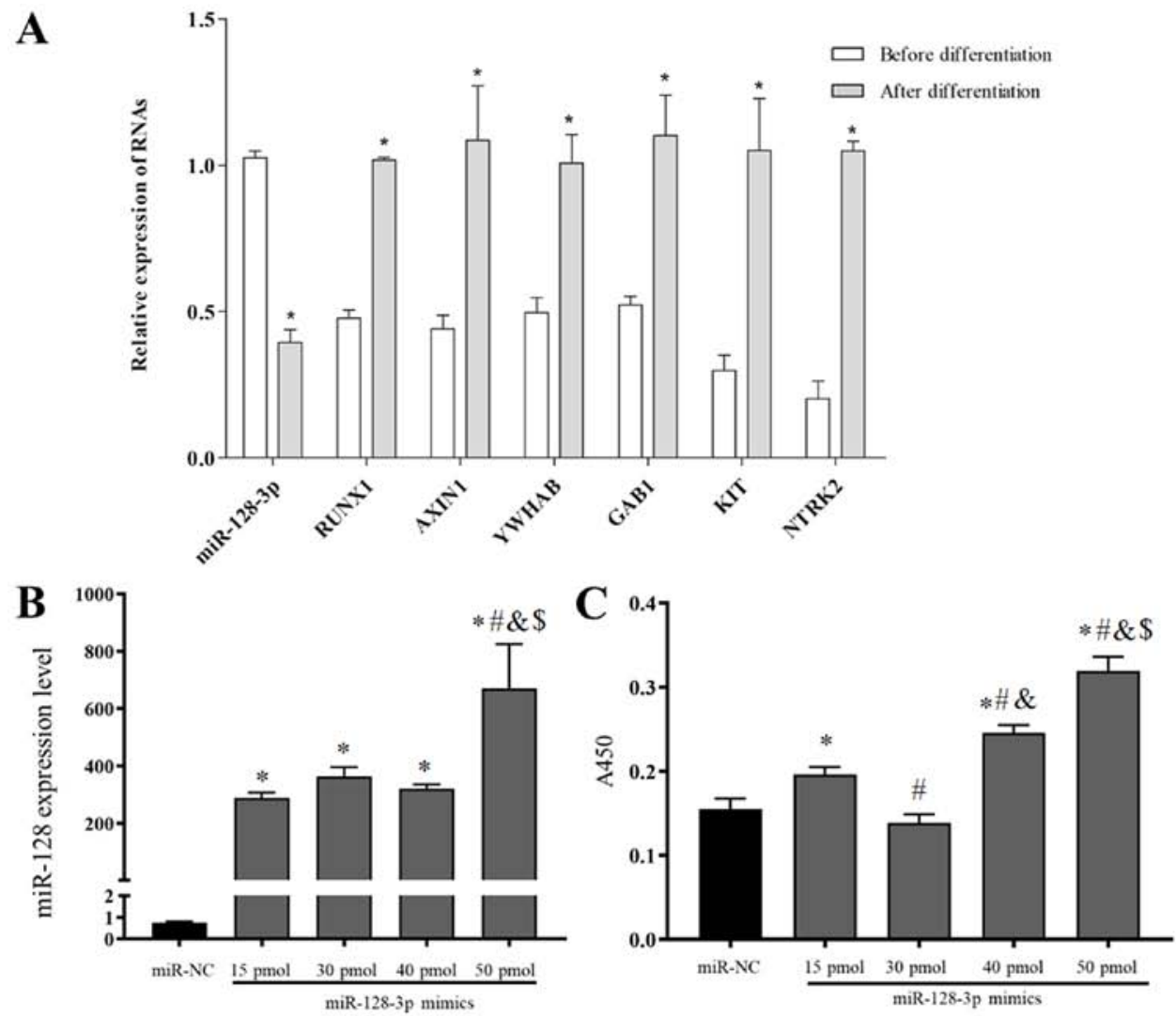

D
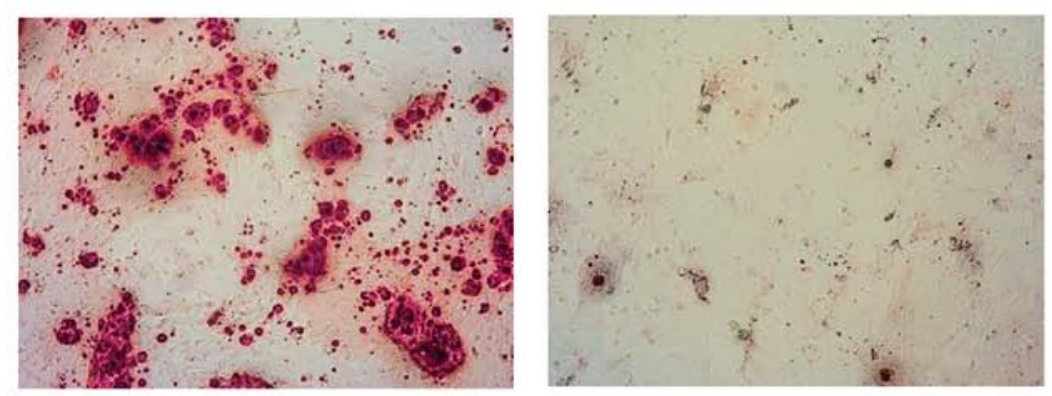

$\mathbf{E}$

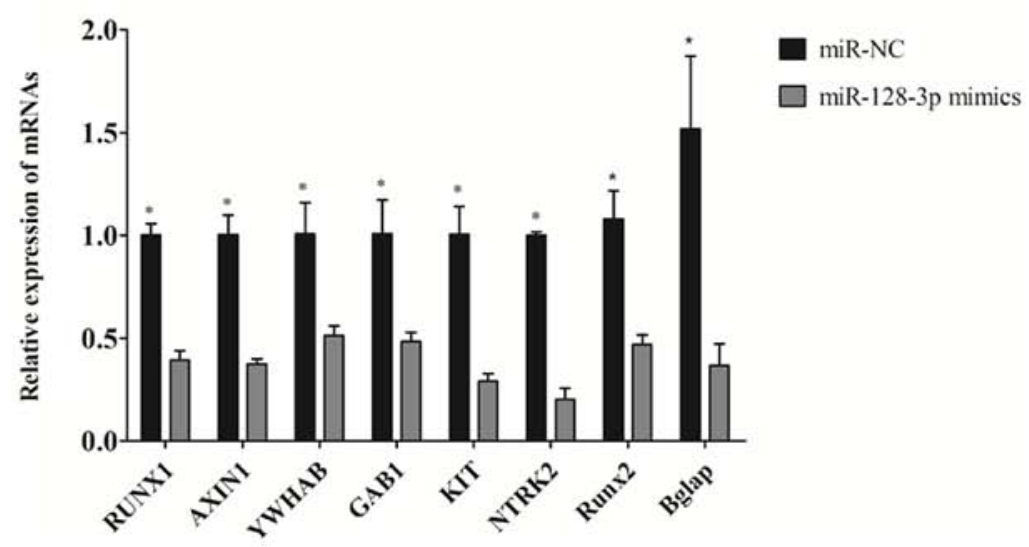

Figure 5. Validation experiments. (A) The expression of miR-128-3p and its target genes in BM MSCs before and after osteoblast differentiation, as determined by RT-qPCR. (B) After transfection of miR-128-3p into rat BM MSCs for $48 \mathrm{~h}$, the expression of miR-128-3p was detected. (C) The effects of miR-128-3p overexpression on the viability of BM MSCs, as evaluated by Cell Counting Kit-8 assay. (D) The effects of miR-128-3p overexpression on osteoblast differentiation, as determined by Alizarin red staining (magnification, x100). (E) The effects of miR-128-3p overexpression on the expression of its target genes, as assessed

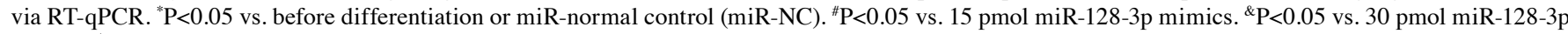
mimics. ${ }^{\$} \mathrm{P}<0.05$ vs. 40 pmol miR-128-3p mimics. miRNA, microRNA; RT-qPCR, reverse transcription- quantitative PCR; BM MSCs, bone marrow derived mesenchymal stem cells; miR NC, miR normal control.

control cells. Ji et al (26) also reported that overexpression of $R U N X 1$ enhanced bone morphogenetic protein 9-induced osteogenic differentiation of murine mesenchymal stem cell line (C3H10T1/2), whereas inhibitory effects were observed 
after knockdown of RUNX1. Saito et al (27) demonstrated that $R U N X 1$ was a downstream effector of Nanog to promote the osteogenic differentiation of C3H10T1/2. In accordance with these studies, the present study also screened $R U N X 1$ as an upregulated gene in differentiated BM-MSCs and its expression was decreased after miR-128 mimic treatment. Further mechanism studies indicated that RUNX1 may exert its promoting roles in osteogenic differentiation by activating the canonical Wnt signaling pathway (including upregulation of $\beta$-catenin, Lef1, Tcf1 and Wnt10b) (25). AXIN1 was previously considered as a negative regulator of the canonical $\mathrm{Wnt} / \beta$-catenin signaling pathway via degradation of $\beta$-catenin with adenomatous polyposis coli (APC), glycogen synthase kinase-3 $\beta$ (GSK-3 $\beta$ ) and Casein kinase 1 (28). Thus, theoretically, upregulated RUNX1 may lead to the downregulation of AXIN1 in the osteogenic differentiation of BM-MSCs $(29,30)$. However, the results of the present study revealed that the expression of AXINI was higher in differentiated compared with undifferentiated BM-MSCs. These controversial findings may be associated with the dual roles of AXINI similar to the reports of its homologous gene AXIN2 in cancers (31). Furthermore, the study of Chimge et al (32) reported that silencing of RUNXI resulted in the downregulation of $A X I N 1$, indicating their synergetic expression trend, which appears to be in agreement with the results of the present study. The present study predicted that RUNXI-AXINI may downregulate GYSI and then IRSI to participate in the osteogenic differentiation. This hypothesis can be indirectly demonstrated by the fact that overexpression of GSK-3 $\beta$ (an AXINI complex component) decreased the mRNA expression level of GYSl (33), while pharmacological inhibition of GSK-3 induced the formation of glycogen bodies (34). Also, an increase in the $I R S-1$ protein level was revealed to inhibit the osteoblastic differentiation of MSCs (35). In addition, insulin-deficiency may trigger the lower expression of its downstream signaling molecule insulin receptor substrate 1 , which is reported to increase the activity of glutaminase (36) and then stimulate osteoblast differentiation from stem cells (37). Accordingly, the miR-128-RUNX1-AXIN1-GYS1-IRS1 axis may be a credible mechanism to explain the osteoblast differentiation processes. In addition to AXINI, RUNXI was also observed to interact with $K I T / G A B 1$ to influence the osteogenic differentiation. KIT is a type 3 transmembrane receptor for stem cell factor (SCF) (38). Activation of the SCF-c-KIT signaling pathway has been revealed to promote the recruitment of stem cells and osteogenesis, which establishes a favorable environment for bone healing and remodeling (38). As an adaptor protein of KIT, GAB1 A complex of $\alpha$-subunits of the $G$ proteins $(G \alpha i 1 / 3)$ and Gab1 can mediate the activation of PI3K-Akt signaling (39), which is suggested to be related with enhanced osteogenesis of MSCs (40).

NTRK2, also known as TRKB, can bind with the TrkB receptor to phosphorylate the downstream Erk1/2, which promotes the expression of transcription factors, such as Runx2 and Osterix that are associated with the osteoblast differentiation of BM-MSCs (41). In accordance with these findings, the present study also revealed that NTRK2 was upregulated in differentiated BM-MSCs and downregulated after
miR-128-mimic transfection, indicating that miR-128-NTRK2 may represent a crucial mechanism for the osteoblast differentiation of BM-MSCs. In addition, the present study also hypothesized that $N T R K 2$ may interact with $G A B 1$ to become involved in osteogenesis of MSCs.

No studies, to the best of the authors' knowledge, have investigated the roles of $Y W H A B$ in the osteogenic differentiation and the regulatory relationship between $Y W H A B$ and miR-128, implying that miR-128-YWHAB interaction may be a novel mechanism for explaining the osteogenic differentiation process of BM-MSCs. The present study predicted PPPICC may be one of the downstream targets of $Y W H A B . P P P I C C$ is a member of the serine/threonine protein phosphatase families. A previous study revealed that a reduction in PP2A promoted the bone formation and the osteoblast differentiation of MSCs through the regulation of bone-related transcription factors such as Osterix (42). Mice deficient in PP5 phosphatase were observed to have increased osteoblast numbers and high bone formation, which is associated with a substantial increase in osteoblast differentiation of MSCs (43). Similar to other members, downregulated $P P P I C C$ by miR-128-YWHAB may also contribute to the osteoblast differentiation.

However, there were some limitations to the present study. First, the target genes of miR-128-3p and their possible interactive downstream genes were predicted, however, the connection between them and their associations with the proliferation and osteoblast differentiation of BM-MSCs still requires additional wet experiments (luciferase reporter assay, co-immunoprecipitation, co-overexpression or co-knockdown) to verify the conclusions. Second, the expression levels and functions of target genes of miR-128-3p should be further tested in human BM-MSCs. Third, in vivo studies should be performed to investigate the differentiation and therapeutic efficiency of BM-MSCs that were transfected with miR-128-3p inhibitors or target genes of miR-128-3p. Fourth, the sample size of our included sequencing datasets was small and thus, it may also be necessary to launch a high-throughput analysis with a larger sample size in order to identify more underlying targets for the osteoblast differentiation of BM-MSCs.

The findings of the present study indicated that miR-128-3p may inhibit the osteoblast differentiation of BM-MSCs by targeted downregulation of RUNX1, YWHAB and NTRK2.

\section{Acknowledgements}

Not applicable.

\section{Funding}

The present study was sponsored by the Interdisciplinary Program of Shanghai Jiao Tong University (Shanghai, China; grant no. YG2017QN21).

\section{Availability of data and materials}

All data generated or analyzed during this study are included in this published article. 


\section{Authors' contributions}

WZ, YZ and CC contributed to the conception and design of this study. WZ and $\mathrm{YZ}$ performed the experiments. WZ, YZ, JC and JW performed the statistical analyses. CY was involved in the interpretation of the data. WZ and $\mathrm{YZ}$ drafted the manuscript. CC edited and revised the manuscript. All authors read and approved the final manuscript.

\section{Ethics approval and consent to participate}

Not applicable.

\section{Patient consent for publication}

Not applicable.

\section{Competing interests}

The authors declare that they have no competing interests.

\section{References}

1. Confalonieri D, Schwab A, Walles H and Ehlicke F: Advanced therapy medicinal products: A guide for bone marrow-derived MSC application in bone and cartilage tissue engineering. Tissue Eng Part B Rev 24: 155-169, 2018.

2. Gopal K, Amirhamed HA and Kamarul T: Advances of human bone marrow-derived mesenchymal stem cells in the treatment of cartilage defects: A systematic review. Exp Biol Med (Maywood) 239: 663-669, 2014

3. Guntur AR and Rosen CJ: The skeleton: A multi-functional complex organ. New insights into osteoblasts and their role in bone formation: The central role of PI3Kinase. J Endocrinol 211: 123-130, 2011

4. Shin YS, Yoon JR, Kim HS and Lee SH: Intra-articular injection of bone marrow-derived mesenchymal stem cells leading to better clinical outcomes without difference in MRI outcomes from baseline in patients with knee osteoarthritis. Knee Surg Relat Res 30: 206-214, 2018.

5. Zhang Y, Liu Y, Wu M, Wang H, Wu L, Xu B, Zhou W, Fan X, Shao J and Yang T: MicroRNA-664a-5p promotes osteogenic differentiation of human bone marrow-derived mesenchymal stem cells by directly downregulating HMGA2. Biochem Biophys Res Commun 521: 9-14, 2020.

6. Ge JB, Lin JT, Hong HY, Sun YJ, Li Y and Zhang CM: MiR-374b promotes osteogenic differentiation of MSCs by degrading PTEN and promoting fracture healing. Eur Rev Med Pharmacol Sci 22: 3303-3310, 2018.

7. Huang J, Meng Y, Liu Y, Chen Y, Yang H, Chen D, Shi J and Guo Y: MicroRNA-320a regulates the osteogenic differentiation of human bone marrow-derived mesenchymal stem cells by targeting HOXA10. Cell Physiol Biochem 38: 40-48, 2016.

8. Tu XM, Gu YL and Ren GQ: miR-125a-3p targetedly regulates GIT1 expression to inhibit osteoblastic proliferation and differentiation. Exp Ther Med 2016 12: 4099-4106, 2016.

9. Wang H, Xie Z, Hou T, Li Z, Huang K, Gong J, Zhou W, Tang K, $\mathrm{Xu}$ J and Dong S: MiR-125b regulates the osteogenic differentiation of human mesenchymal stem cells by targeting BMPR1b. Cell Physiol Biochem 41: 530-542, 2017.

10. Zhang S, Liu Y, Zheng Z, Zeng X, Liu D, Wang C and Ting K: MicroRNA-223 suppresses osteoblast differentiation by inhibiting DHRS3. Cell Physiol Biochem 47: 667-679, 2018.

11. Zhang W, Yao C, Wei Z and Dong Q: miR-128 promoted adipogenic differentiation and inhibited osteogenic differentiation of human mesenchymal stem cells by suppression of VEGF pathway. J Recept Signal Transduct Res 37: 217-223, 2017.

12. Chang CC, Ven $\varnothing$ MT, Chen L, Ditzel N, Le D, Dillschneider P, Kassem $\mathrm{M}$ and Kjems J: Global microrna profiling in human bone marrow skeletal-stromal or mesenchymal-stem cells identified candidates for bone regeneration. Mol Ther 26: 593-605, 2017.
13. Sun Y, Cai M, Zhong J, Yang L, Xiao J, Jin F, Xue H, Liu X, Liu H, Zhang Y, et al: The long noncoding RNA lnc-ob1 facilitates bone formation by upregulating Osterix in osteoblasts. Nat Metab 1: 485-496, 2019.

14. Love MI, Huber W and Anders S: Moderated estimation of fold change and dispersion for RNA-seq data with DESeq2. Genome Biol 15: 550, 2014.

15. R Core Team. R: A language and environment for statistical computing. R Foundation for Statistical Computing, Vienna, Austria. 2012. URL http://www.R-project.org/.

16. Dweep H and Gretz N: miRWalk2.0: A comprehensive atlas of microRNA-target interactions. Nat Methods 12: 697-697, 2015.

17. Kohl M, Wiese S and Warscheid B: Cytoscape: Software for visualization and analysis of biological networks. Methods Mol Biol 696: 291-303, 2011

18. Szklarczyk D, Franceschini A, Wyder S, Forslund K, Heller D, Huerta-Cepas J, Simonovic M, Roth A, Santos A, Tsafou KP, et al: STRING v10: Protein-protein interaction networks, integrated over the tree of life. Nucleic Acids Res 43 (Database Issue): D447-D452, 2015.

19. Tang Y, Li M, Wang J, Pan Y and Wu FX: CytoNCA: A cytoscape plugin for centrality analysis and evaluation of protein interaction networks. Biosystems 127: 67-72, 2015.

20. Kuleshov MV, Jones MR, Rouillard AD, Fernandez NF, Duan Q, Wang Z, Koplev S, Jenkins SL, Jagodnik KM, Lachmann A, et al: Enrichr: A comprehensive gene set enrichment analysis web server 2016 update. Nucleic Acids Res 44: W90-W97, 2016.

21. Livak KJ and Schmittgen TD: Analysis of relative gene expression data using real-time quantitative PCR and the 2(-Delta Delta C(T)) method. Methods 25: 402-408, 2001.

22. Zou W, Greenblatt MB, Brady N, Lotinun S, Zhai B, de Rivera H, Singh A, Sun J, Gygi SP, Baron R, et al: The microtubule-associated protein DCAMKL1 regulates osteoblast function via repression of Runx2. J Exp Med 210: 1793-1806, 2013.

23. Matta C, Szúcs-Somogyi C, Kon E, Robinson D, Neufeld T, Altschuler N, Berta A, Hangody L, Veréb Z and Zákány R: Osteogenic differentiation of human bone marrow-derived mesenchymal stem cells is enhanced by an aragonite scaffold. Differentiation 107: 24-34, 2019.

24. Motohashi N, Alexander MS, Casar JC and Kunkel LM: Identification of a novel microRNA that regulates the proliferation and differentiation in muscle side population cells. Stem Cells Dev 21: 3031-3043, 2012.

25. Luo Y, Zhang Y, Miao G, Zhang Y, Liu Y and Huang Y: Runx1 regulates osteogenic differentiation of BMSCs by inhibiting adipogenesis through Wnt/ $\beta$-catenin pathway. Arch Oral Biol 97: 176-184, 2019.

26. Ji C, Xiaohua L, Li X, Tingting Y, Chaoqun D and Jinyong L: RUNX1 plays an important role in mediating BMP9-Induced osteogenic differentiation of mesenchymal stem cells line C3H10T1/2, murine multi-lineage cells lines $\mathrm{C} 2 \mathrm{C} 12$ and MEFs. Int J Mol Sci 18: 1348, 2017.

27. Saito T, Ohba S, Yano F, Seto I, Yonehara Y, Takato T and Ogasawara T: Runx1 and Runx3 are downstream effectors of nanog in promoting osteogenic differentiation of the mouse mesenchymal cell line C3H10T1/2. Cell Reprogram 17: 227-234, 2015.

28. Nakamura T, Hamada F, Ishidate T, Anai K, Kawahara K, Toyoshima K and Akiyama T: Axin, an inhibitor of the Wnt signalling pathway, interacts with beta-catenin, GSK-3beta and APC and reduces the beta-catenin level. Genes Cells 3: 395-403, 1998.

29. Figeac $\mathrm{N}$ and Zammit PS: Coordinated action of Axin1 and Axin2 suppresses $\beta$-catenin to regulate muscle stem cell function. Cell Signal 27: 1652-1665, 2015.

30. Gwak J, Hwang SG, Park HS, Choi SR, Park SH, Kim H, Ha NC, Bae SJ, Han JK, Kim DE, et al: Small molecule-based disruption of the Axin/ $\beta$-catenin protein complex regulates mesenchymal stem cell differentiation. Cell Res 22: 237-247, 2012.

31. Wu ZQ, Brabletz T, Fearon E, Willis AL, Hu CY, Li XY and Weiss SJ: Canonical Wnt suppressor, Axin2, promotes colon carcinoma oncogenic activity. Proc Natl Acad Sci USA 109: 11312-11317, 2012.

32. Chimge NO, Little GH, Baniwal SK, Adisetiyo H, Xie Y,Zhang T, O'Laughlin A, Liu ZY, Ulrich P, Martin A, et al: RUNX1 prevents oestrogen-mediated AXIN1 suppression and $\beta$-catenin activation in ER-positive breast cancer. Nat Commun 7: 10751, 2016. 
33. Wang Y, Wang Y, Zhong T, Guo J, Li L, Zhang H and Wang L: Transcriptional regulation of pig GYS1 gene by glycogen synthase

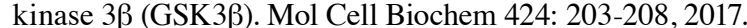

34. Chen RJ, Zhang G, Garfield SH, Shi YJ, Chen KG, Robey PG and Leapman RD: Variations in glycogen synthesis in human pluripotent stem cells with altered pluripotent states. PLoS One 10: e0142554, 2015.

35. Contaldo C, Myers TJ, Zucchini C, Manara MC, Chiodoni C, Colombo MP, Nicoletti G, Lollini PL, Li T, Longobardi L, et al: Expression levels of insulin receptor substrate-1 modulate the osteoblastic differentiation of mesenchymal stem cells and osteosarcoma cells. Growth Factors 32: 41-52, 2014

36. Ardawi MS: The maximal activity of phosphate-dependent glutaminase and glutamine metabolism in the colon and the small intestine of streptozotocin-diabetic rats. Diabetologia 30 : 109-114, 1987.

37. Yu Y, Newman H, Shen L, Sharma D, Hu G, Mirando AJ, Zhang H, Knudsen E, Zhang GF, Hilton MJ and Karner CM: Glutamine metabolism regulates proliferation and lineage allocation in skeletal stem cells. Cell Metab 29: 966-978.e4, 2019.

38. Matsumoto T, Ii M, Nishimura H, Shoji T, Mifune Y, Kawamoto A, Kuroda R, Fukui T, Kawakami Y, Kuroda T, et al: Lnk-dependent axis of SCF-cKit signal for osteogenesis in bone fracture healing. J Exp Med 207: 2207-2223, 2010.

39. Zhang YM,Zhang ZQ, Liu YY,Zhou X, Shi XH, Jiang Q, Fan DL and Cao C: Requirement of Gai1/3-Gab1 signaling complex for keratinocyte growth factor-induced PI3K-Akt-mTORC1 activation. J Invest Dermatol 135: 181-191, 2015.
40. Liu L, Shao L, Li B, Zong C, Li J, Zheng Q, Tong X, Gao C and Wang J: Extracellular signal-regulated kinase1/2 activated by fluid shear stress promotes osteogenic differentiation of human bone marrow-derived mesenchymal stem cells through novel signaling pathways. Int J Biochem Cell Biol 43: 1591-1601, 2011

41. Liu Q, Lei L, Yu T, Jiang T and Kang Y: Effect of brain-derived neurotrophic factor on the neurogenesis and osteogenesis in bone engineering. Tissue Eng Part A 24: 1283-1292, 2018.

42. Hirohiko O, Kaya Y, Hiroyuki M, Jumpei T, Kazuhiko O, Tatsuji $\mathrm{H}$ and Akihito Y: Role of protein phosphatase 2A in osteoblast differentiation and function. J Clin Med 6: 23, 2017.

43. Stechschulte LA, Ge C, Hinds TD, Sanchez ER and Lecka-Czernik B: Protein phosphatase PP5 controls bone mass and the negative effects of rosiglitazone on bone through reciprocal regulation of PPAR $\gamma$ (peroxisome proliferator-activated receptor $\gamma$ ) and RUNX2 (runt-related transcription factor 2). J Biol Chem 291: 24475-24486, 2016.

(7) $\odot$ This work is licensed under a Creative Commons Attribution-NonCommercial-NoDerivatives 4.0 International (CC BY-NC-ND 4.0) License. 